Martín-Albo Huertas, L. (2021). Los españolismos en el caló de George Borrow: préstamos

e invenciones en la traducción del evangelio de san Lucas

RILEX. Revista sobre investigaciones léxicas, 4/I, pp. 149-182.

\title{
LOS ESPAÑOLISMOS EN EL CALÓ DE GEORGE BORROW: PRÉSTAMOS E INVENCIONES EN LA TRADUCCIÓN DEL EVANGELIO DE SAN LUCAS
}

\section{SPANISH TERMS IN GEORGE BORROW'S CALÓ. LOANS AND INVENTIONS IN HIS TRANSLATION OF SAINT LUKA'S GOSPEL}

\author{
Lourdes Martín-Albo Huertas \\ IES Avenida de los Toreros (Madrid) \\ lourdesmalbo@hotmail.com
}

\begin{abstract}
RESUMEN
En este trabajo se presenta un estudio de los términos españoles usados por George Borrow en una de las tres versiones de su traducción al caló de un fragmento del Evangelio de San Lucas, mediante su comparación con las soluciones que ofrecen las otras dos versiones. Dicho estudio brinda un curioso panorama de la evolución léxica del caló de Borrow, en el que parecen mezclarse los vocablos españoles tomados de diversas fuentes con las invenciones de términos calós o los préstamos de otros dialectos del romaní. Todo ello apunta a la dificultad actual con que nos encontramos de cara al estudio de esta lengua tan relacionada con el español.
\end{abstract}

Palabras clave: Dialectología; caló; George Borrow.

\begin{abstract}
This work presents a study on the Spanish terms used by George Borrow in one of the three versions of his translation of a fragment of St Luke's Gospel into Caló, of a fragment of the Saints Luke's Gospel, by means of a comparison with the solutions offered in the other two versions. This study offers a revealing overview of the lexical evolution of Borrow's Caló, in which Spanish words seem to mix up with the inventions of terms or loans from other Romani dialects. All of this points to the current difficulty that we still face when studying Caló.
\end{abstract}

Keywords: Dialectology; Caló; George Borrow. 


\section{PRESENTACIÓN ${ }^{1}$}

George Borrow es uno de los escritores británicos del siglo XIX más célebres en su tierra natal gracias a obras como The Zincali, The Bible in Spain o Lavengro. Sin embargo, aunque gran parte de su fama le llegó por sus escritos sobre España, país que recorrió en su afán evangelizador, aquí es apenas conocido y recordado. Y ello a pesar de que fue el primer autor que se ocupó sistemáticamente de una de las lenguas habladas en España, el caló, y de que fue también el primero en publicar una obra entera escrita en dicha lengua. Pese a sus invectivas contra los gitanos (y contra los españoles y portugueses en general), se preocupó por difundir las Sagradas Escrituras entre ellos usando su propia lengua, aunque resultó ser este un empeño un tanto vano debido al nivel de analfabetismo de sus hablantes y a la desintegración que el caló presentaba ya en su época. Borrow, que era un enamorado de las lenguas y de la lingüística, se esforzó en ir puliendo sus traducciones, por lo que nos encontramos con dos versiones del Evangelio de San Lucas en caló: el Embéo e majaró Lucas (1837) y el Criscote e majaró Lucas² (1872). A estas se suman dos hallazgos: el fragmento del mismo Evangelio, bilingüe en caló e inglés, que aparece al final de otra obra del autor, The Zincali (1841), así como una curiosa edición del Embéo en español y caló, preparada por el sacerdote Alberto González Caballero (1998).

Por todo ello, el presente trabajo pretende recuperar esa primera obra en caló, la traducción del Evangelio de San Lucas, y estudiar en parte su complejo proceso de composición partiendo del análisis de una particularidad léxica llamativa: el uso de términos españoles en la traducción. Para ello, se ha seleccionado un pasaje determinado: los versículos 1 a 28 del capítulo 21 del Evangelio de San Lucas, que es el fragmento que aparece traducido al final de The Zincali. La razón de dicha elección es que este es el único pasaje del cual disponemos tres versiones en caló del propio autor —la del Embéo, la del Criscote y la de The Zincali-, por lo que su estudio puede ofrecer

\footnotetext{
${ }^{1}$ Esta investigación está basada en un trabajo de fin de máster defendido en la UNED.

${ }^{2}$ A partir de ahora se citarán como Embéo y Criscote.
} 
una mayor información sobre la evolución del léxico caló en los textos de Borrow. En efecto, su comparación ha evidenciado numerosas diferencias y vacilaciones en todos los niveles lingüísticos y ha arrojado abundante material para su análisis y comentario.

En el estudio que nos ocupa, se ha partido de los versículos en los que aparecen vocablos españoles en el Embéo y se han cotejado con esos mismos versículos de las otras dos versiones para determinar si el autor recurría en ellos a la misma voz o expresión española, a otra o a una caló; en este último caso, se ha intentado determinar de dónde podía haber tomado Borrow dichas voces calós. Para ello se han tomado como referencia dos de los diccionarios caló-español más conocidos: los de Quindalé (1867) y Pabanó (1915). Asimismo, se han recabado datos de otras obras que pudieran aportar información sobre los vocablos estudiados, como la mencionada traducción de González Caballero, la edición del nuevo Testamento de Felipe Scío de 1826 —en la que probablemente se basó Borrow tanto para preparar su publicación del Nuevo Testamento que difundió en España como para traducir al caló el Evangelio de San Lucas- y el trabajo de Dietze (2012)³. Para facilitar la comprensión y el cotejo de las versiones, se han incluido tablas sinópticas en las que se recogen los fragmentos aludidos pertenecientes a las cinco obras: Embéo, The Zincali, Criscote, González Caballero y Scío.

\section{BREVE RESEÑA BIOGRÁFICA DE GEORGE BORROW}

George Henry Borrow ${ }^{4}$ nació el 5 de julio de 1803 en Dumpling Green (East Dereham, Norfolk) y fue el segundo hijo de Thomas Borrow, capitán de la milicia, y de Anne Perfrement.

\footnotetext{
${ }^{3}$ Dietze (2012) hace una comparación entre las versiones de Embéo y Criscote de los capítulos 1 a 7 completos más los versículos 1 a 25 del capítulo 8. En cuanto a esta obra, tesis doctoral de su autor, debido a la situación de alarma sanitaria iniciada en marzo de 2020 no me ha sido posible consultarla en su edición de 2017 a cargo de AV Akademikervelag. La he manejado en la versión en PDF disponble en https://n9.cl/7o36w [15-01-21].

${ }^{4}$ Para la redacción de esta reseña sobre su vida se han consultado las principales biografías de Borrow: Knapp, 1899; Borrow, 1901 [1851]; Jenkins, 1912; Thomas, 1912 y Shorter, 1913.
} 
En 1810 el joven Borrow tiene un primer encuentro con los gitanos en Huntingdonshire, donde conoce a Ambrose Smith, con el que comienza una estrecha relación de hermanamiento. Entre 1812 y 1815 la familia se ve obligada a mudarse, primero a Irlanda y luego a Escocia, estancias que George aprovecha para aprender las lenguas locales. En 1816 vuelven a Norfolk, donde se instalan definitivamente. Ambrose Smith le ayuda a aprender el anglorromaní y, gracias a su facilidad para hablar idiomas y a sus dotes oratorias, los amigos gitanos le otorgan el apelativo de Lavengro 'el maestro de la palabra', que dará título a una de sus obras autobiográficas.

Tras la muerte de su padre en febrero de 1824, se traslada a Londres para intentar ganarse la vida como escritor. En 1832 se opera el gran cambio en su vida, cuando gracias a una familia con la que lo unen relaciones de amistad, los Skepper de Oulton Hall (Suffolk), y de la que forma parte su futura esposa, la viuda Mrs. Mary Clarke, conoce a un influyente miembro de la British and Foreign Bible Society ${ }^{5}$. Dicha asociación lo contrata como colportor y le encarga, primero, la supervisión de la edición en San Petersburgo del Nuevo Testamento traducido al manchú y, después, la promoción del Nuevo Testamento en Portugal y España. Para esta última misión llega a Lisboa a mediados de noviembre de 1835 y, tras una estancia de unos dos meses en el país, decide pasar a España para tantear el terreno.

El 6 de enero de 1836 entra en Badajoz, donde se encuentra por primera vez con los gitanos españoles. Decide permanecer unos diez días en la ciudad, ocupado en traducir el capítulo 15 del Evangelio de San Lucas al caló. Tras dicha estancia, parte para Madrid, donde se establece con el objetivo de obtener el permiso de impresión del Nuevo Testamento en castellano sin anotaciones ni añadidos, como era costumbre en la Sociedad Bíblica. Continúa

\footnotetext{
${ }^{5}$ Sociedad de confesión cristiana reformada fundada en 1804, que se ocupa de difundir la lectura directa de la Biblia, sin notas ni comentarios (Shorter, 1913, pp. 155-157).

${ }^{6}$ La misión del colportor de la Sociedad Bíblica consistía, en general, en ser enviado a otros países donde no predominara la religión protestante para ayudar en la difusión de la Biblia sin anotaciones ni comentarios.
} 
con la traducción del Evangelio de San Lucas mientras espera lograr las licencias del gobierno, que llegan en junio de 1836 y, tras terminar la edición del Nuevo Testamento en español, comienza un largo viaje de cinco meses por el norte de la Península vendiendo ejemplares, después del cual vuelve a Madrid para establecerse como librero y editor. Pide permiso a la Sociedad Bíblica para imprimir dos traducciones del Evangelio de San Lucas, tanto la suya al caló, Embéo e majaró Lucas (1837), como otra al vasco hecha por un tal doctor Oteiza ${ }^{7}$. Tras conseguir el visto bueno, la impresión comenzó a finales de 1837, a la vez que se consolidaba un gobierno conservador. Borrow anunció sus libros en periódicos y carteles, algo que el nuevo ejecutivo se tomó como un desafío a su autoridad. El 14 de enero de 1838 recibió una orden del gobernador civil de Madrid que decretaba el embargo de su edición del Nuevo Testamento. Cuando aparecieron a la venta los Evangelios de San Lucas en caló y en vasco, el gobierno montó en cólera y Borrow fue arrestado y encarcelado el 1 de mayo de 1838, pero recuperó su libertad el 11 de mayo gracias a las gestiones del embajador británico.

A raíz de todo ello, las relaciones con la Sociedad Bíblica, descontenta además por sus numerosos gastos, sufren un fuerte revés y es llamado a Londres, si bien, tras arreglar sus diferencias, le permiten regresar a Madrid.

En abril de 1839 se instala en Sevilla, adonde se trasladan también Mrs. Clarke y su hija. A mediados de agosto, tras nuevos desacuerdos, la Sociedad Bíblica le comunica que da por zanjada definitivamente la relación con él. No obstante, permanece en Sevilla dedicado principalmente a escribir una de sus obras destacadas, The Zincali (1841).

Borrow y Mrs. Clarke deciden volver a Gran Bretaña a principios de abril de 1840 y, tras contraer matrimonio, se instalan en Oulton Cottage, la propiedad de la esposa en Lowestoft, Suffolk. Ella percibía rentas de varias

\footnotetext{
${ }^{7}$ No se sabe gran cosa de este autor. El título de su obra es Evangelioa San Lucasen Guissan. El Evangelio según S. Lucas, traducido al vascuence. Madrid: Imprenta de la Compañía Tipográfica, 1838.
} 
propiedades, lo que permite a su marido, que contaba por entonces con 37 años, dedicarse a escribir y viajar. Comienza los preparativos de la impresión de The Zincali, que había sido compuesto básicamente en España, y a raíz de su publicación inicia una relación de amistad con Richard Ford ${ }^{8}$, quien le aconseja que hable en sus obras de sus experiencias personales y aventuras. The Zincali vio la luz en Londres en noviembre de 1841 y tuvo una buena acogida, aunque no excepcional.

A principios de 1843 publica The Bible in Spain ${ }^{9}$, un gran éxito que narra sus andanzas en la Península y que le reportó una fama inmediata en gran parte de Europa y en Estados Unidos. Poco después comienza su tercer trabajo original, Lavengro (1851), a instancias de sus amigos, que le pedían que contara los acontecimientos de su vida en los veinte años anteriores a los narrados en The Bible in Spain. La obra se publica finalmente en febrero de 1851, pero las críticas fueron unánimemente desfavorables, ya que se le achacaban inverosimilitud, falta de hilo argumental y exagerado antipapismo.

Tras una serie de excursiones por las islas británicas en las que recopila información filológica sobre las lenguas celtas de la zona que usará en obras posteriores, en febrero de 1854 comienza a ocuparse de la redacción de The Romany $R y e^{10}$, su segunda obra autobiográfica, que se publicará finalmente en mayo de 1857 y cosechará críticas tanto favorables como desfavorables.

En verano de 1860 la familia se muda a Londres, donde el autor finaliza y publica en 1862 una de sus mejores obras: Wild Wales ${ }^{11}$, en la que recoge sus

\footnotetext{
${ }^{8}$ Londres, 1796-Exeter, 1858. Fue un conocido hispanista y viajero inglés. Por aquel entonces, Ford estaba redactando su obra más conocida: Hand-Book for Travellers in Spain and Readers at Home, London, Murray, 1845. Se basaba en las vivencias de su viaje de tres años por España, entre 1829 y 1831 (Knapp, 1899, I, p. 358).

${ }^{9}$ Borrow, G. (1843). The Bible in Spain; or, the Journeys, Adventures and Imprisionments of an English man, in an attempt to circulate the Scriptures in the Peninsula. By George Borrow, Author of "The Gypsies of Spain". London: John Murray.

${ }^{10}$ Borrow, G. (1857). The Romany Rye. A sequel to Lavengro. London: John Murray.

${ }^{11}$ Borrow, G. (1862). Wild Wales: Its People, Language and Scenery, By George Borrow, Author of "The Bible in Spain", etc. London: John Murray.
} 
andanzas por Gales. En general, las revistas literarias, o bien pasaron por alto esta publicación, o bien la criticaron negativamente.

Dos años después de la muerte de su esposa, ocurrida en 1869, comienza a preparar un vocabulario del anglorromaní, así como la reedición de la traducción del Evangelio de San Lucas al caló que le había pedido la Sociedad Bíblica, el llamado Criscote e majaró Lucas (1872). Posteriormente se centró en su última obra, el vocabulario llamado Romano Lavo-Lill ${ }^{12}$, que consistía en un listado de unas 1300 palabras del anglorromaní, al que se añadió una recopilación de poesía. La nueva generación de filólogos del romaní recibió la obra de forma muy crítica, ya que le achacaban diversos defectos de método, contenido y presentación.

Hacia el final del verano de 1874 vuelve a su casa de Oulton, donde fallece el 26 de julio de 1881 a la edad de 78 años.

\section{EL CALÓ}

Por sus rasgos tipológicos el caló es una lengua mixta pararromaní que se originó por la dialectalización del romaní. Esta última lengua indoeuropea procede de la familia neoindia, que deriva a su vez de la rama indoaria. El romaní sufrió un proceso de dialectalización mediante el cual se formaron dos grandes grupos: los dialectos puros, que son aquellos que mantienen tanto el vocabulario como la morfosintaxis del romaní, y los mixtos o pogadolectos ${ }^{13}$, que han adoptado la morfosintaxis de la lengua mayoritaria de la zona en la que se asentaron sus hablantes (Matras, 2002, p. 13; Adiego, 2004, pp. 211-218).

\footnotetext{
${ }^{12}$ Borrow, G. (1905 [1874]). Romano Lavo-Lil, Word Book of the Romany or, English Gypsy Language with Specimens of Gypsy Poetry, and an Account of Certain Gypsyries or Places inhabited by them, and of various Things relating to Gypsy Life in England. By George Borrow, Author of "Lavengro", "The Romany Rye", "The Gypsies of Spain", "The Bible in Spain", etc. London: John Murray.

${ }^{13}$ El término pogadolecto procede de la expresión pogadi chib 'broken language', 'lengua truncada', que hace alusión a estas lenguas que han perdido su sistema morfosintáctico, pero mantienen gran parte de su léxico (Adiego, 2004, pp. 217-218; Buzek, 2008, p. 500). Dicho vocablo es un neologismo ideado por los lingüistas romaníes para hablar del tipo de lenguas mixtas típicas de este grupo dialectal (Jiménez González, 2009, p.153).
} 
Así pues, el romaní dio lugar en Europa a una serie de lenguas mixtas entre las que se encuentra el caló, que es el resultado de la mezcla del léxico romaní con la morfosintaxis del español. Su estudio resulta complicado por varios motivos: en primer lugar, es un idioma que ya en época de Borrow estaba agonizante y, de hecho, a día de hoy se ha perdido. Como indican Buzek y Krinková, los intentos de revitalización han fracasado y dentro de poco solo quedarán los gitanismos que han entrado en el español coloquial (2020, p. 173). En segundo lugar, carecemos de suficientes testimonios fiables, ya que los textos con los que contamos son principal y casi exclusivamente los de Borrow, lo que nos lleva a la cuestión del origen y la calidad de su caló.

Él mismo cuenta que aprendió el anglorromaní, otro de los dialectos pararromaníes, en Inglaterra, así como que tuvo contacto con otros gitanos de Europa y que los gitanos pacenses, andaluces y madrileños le enseñaron su lengua. De ahí se deriva el problema principal: su caló recibió influencias de muchos dialectos, tanto del pararromaní como del propio caló (Hancock, 1997, pp 200-206; Dietze, 2012, p. 76) Asimismo, al menos en sus obras más tempranas, notamos el peso del idioma español, ya que, cuando desconocía el término caló, solía usar uno castellano, como vamos a ver después.

Otro problema que dificulta el estudio del caló de Borrow es la presencia en su obra de las invenciones de la llamada afición de Sevilla, como se denominaba a los entusiastas simpatizantes del modo de vida gitano y de su cultura, que querían presumir de saber caló y se inventaban muchos términos con procedimientos poco ortodoxos, buscando muchas veces el chiste. Las invenciones de la afición dieron pie a una variedad de formas de creación de neologismos, desde el calco de una palabra o parte de una palabra española erróneamente segmentada con la que se relacionaba por significado o por mero parecido fonético ${ }^{14}$, hasta la gitanización de términos españoles por el

\footnotetext{
${ }^{14}$ Sirva como ejemplo de este tipo de invenciones el clásico sichaguillo 'monaguillo', que se creó segmentando la palabra española en mona y guillo y anteponiendo a esta última parte el término caló sicha 'mona'.
} 
procedimiento de añadirle un prefijo o sufijo caló ${ }^{15}$. De todo ello encontramos ejemplos en las obras de Borrow, a pesar de que él mismo denunció este proceder de los aficionados (1841, II, p. 58).

Asimismo, hay que tener en cuenta a la hora de estudiar el caló de esta época la apropiación de voces de la germanía. Esta era la jerga de los gremios de ladrones y rufianes de los siglos XVI y XVII, que estaba compuesta principalmente por palabras españolas a las que se les cambiaba el sentido para cumplir con su función críptica. No tenía en su origen relación ninguna con el caló, aunque la sociedad de la época acabó identificando ambos lenguajes debido a la mala fama compartida de sus hablantes (Buzek, 2010, p. 18). Probablemente la germanía ya constituía una jerga cerrada cuando llegaron los gitanos, y la mezcla entre esta y el caló se realizó con lentitud a partir del XVII (Clavería, 1951, pp. 16-17). Hay ciertas pruebas que indican que los gitanos utilizaban vocablos germanescos (Adiego, 2005, p. 133). En cuanto a su uso por Borrow, Dietze (2012, pp. 78-79) mantiene que pudo aprender algunos términos de esta jerga durante su estancia en la cárcel de Madrid en mayo de 1838, así como que consultó la obra de Juan Hidalgo ${ }^{16}$ para componer The Zincali.

No está claro si todos esos tipos de neologismos y préstamos tomaron carta de naturaleza en el caló a partir de la segunda mitad del XIX. Dietze (2012, p. 60) opina que sí, pero Adiego (2005, p. 141 n. 11) lo pone en duda y limita el fenómeno al ámbito de los aficionados. Lo cierto es que el fenómeno de la transformación de esta lengua en dicha época es un tema complejo e interesante que merecería un estudio a fondo, porque hay indicios de que tanto el uso de los neologismos de la afición como de los préstamos de la germanía no eran una cuestión accidental, sino que esos términos conformaron la lengua de un modo especial. Sí se constata su influencia en los

\footnotetext{
${ }^{15}$ Buzek, 2011, pp. 101-103. Así ocurre, por ejemplo, en rabizarar 'rabiar' o vendizarar 'vender'. ${ }^{16}$ Hidalgo, J. (1609). Romances de germanía de varios autores, con el vocabulario por la orden de a. b. c. para declaración de sus términos y lengua. Barcelona: Cormellas.
} 
textos con los que contamos, que se muestran todos mediatizados por los círculos de los aficionados, como los escritos del propio Borrow y los diccionarios posteriores. Entre estos destacan los repertorios de Quindalé (1867) ${ }^{17}$ y Pabanó $(1915)^{18}$, utilizados en este estudio, así como el de Trujillo ${ }^{19}$.

De todo ello se deduce, asimismo, algo a lo que apunta este trabajo: que los conocimientos de Borrow acerca del caló no eran tan profundos como pretendía hacer creer, y esto se refleja en varios aspectos de su obra. La propia existencia de tres traducciones diferentes de un mismo texto evangélico podría sugerir cierta inseguridad en el manejo de la lengua, como se verá después.

\section{LAS VERSIONES DEL T'EX'TO ES'T'UDIADO}

Las tres versiones estudiadas, que se redactaron en principio en el intervalo comprendido entre 1837 y 1872, son relativamente distintas, en especial la traducción que se recoge en The Zincali. Dos de ellas provienen de sendas traducciones completas del Evangelio de San Lucas al caló: la del Embéo (1837, pp. 146-150) y la del Criscote (1872, pp. 97-99), a las que se añade el fragmento que aparece al final de The Zincali (1841, II, *130-*134) ${ }^{20}$. Dado que ya a primera vista se puede comprobar que se trata de textos bastante diferentes, se planteó que podría resultar interesante realizar una comparación

\footnotetext{
${ }^{17}$ Francisco Quindalé era el seudónimo de Francisco de Sales Mayo. Fue, tras Borrow, el primero que estudió el caló con perspectiva filológica, aunque pertenecía al círculo de los aficionados.

${ }^{18}$ F. M. Pabanó, seudónimo de Félix Manzano López, compuso una obra valiosa porque es la primera de este estilo que cita las fuentes y porque tiene claro que el origen de gran parte del vocabulario que se maneja en estos repertorios no es propiamente caló, aunque finalmente el autor no es capaz de señalar de dónde vienen muchos de los términos que recoge. 19 El de Trujillo fue el primer diccionario caló publicado en España (Trujillo, E. (1844). Vocabulario del dialecto gitano. Madrid: Imprenta de D. Enrique Trujillo). Adiego (2005, pp. 139-140) plantea que muchos de los procedimientos de creación de términos usados por la afición fueron invención de este autor.

${ }^{20}$ En la primera edición de The Zincali el vocabulario y el apartado llamado Miscellanies aparecen con paginación propia dentro del volumen II, iniciándose la notación desde el número 1 , pero precedida de un asterisco.
} 
entre los tres para ver la evolución en el uso de vocablos españoles que usó el autor inglés en sus traducciones al caló a lo largo de su vida.

En cuanto a la cronología de estos tres textos, si nos guiamos por la fecha de publicación de cada uno de ellos, el orden sería el siguiente: en primer lugar, el Embéo (1837); en segundo, la traducción recogida en la miscelánea de The Zincali (1841) y, por último, la versión del Criscote (1872). Sin embargo, como veremos más adelante, hay razones para pensar que el texto de The Zincali podría ser el más antiguo.

El Embéo destaca como la primera obra importante del autor. Su título original era Embéo e Majaró Lucas, brotoboro randado andré la chipé griega, acana chivado andré o Romanó, o chipé es Zincales de Sesé. El Evangelio según San Lucas, traducido al Romaní, o dialecto de los gitanos de España. Fue publicada en Madrid en febrero de 1838, a pesar de que en la portada consta el año de 1837. Como hemos visto, en esa época Borrow estaba asentado en la capital como colportor, haciéndose cargo de la oficina de la British and Foreign Bible Society.

En cuanto al texto original, sabemos (Knapp, 1899, I, pp. 224-233; Buzek, 2011, p. 131) que para sus ediciones del Nuevo Testamento en español Borrow utilizó una de las traducciones de la Biblia más usuales de la época, la del sacerdote Felipe Scío de San Miguel $^{21}$, ya que la propia Sociedad Bíblica había recurrido a esta traducción para imprimir varias ediciones del Nuevo Testamento y de toda la Biblia en español entre los años 1819 y 1837 (Bullen, 1857, pp. 663-664), pero ya descargada de todas las notas y comentarios para adecuarla a los usos de la confesión anglicana. Lo más probable es que Borrow usara la edición de 1826 (Scío, 1826), impresa en Londres a cargo de

\footnotetext{
${ }^{21}$ Felipe Scío y Riaza o Felipe de San Miguel (1738-1796) fue un sacerdote escolapio español que publicó entre 1790 y 1793 una traducción de la Vulgata. La suya era la primera Biblia en español que se imprimió en España y llevó por título La Biblia Vulgata latina traducida en español y anotada conforme al sentido de los Santos Padres y expositores catholicos, por el Rmo. P. Phelipe Scio de S. Miguel, de las Escuelas Pías, Obispo electo de Segovia. Valencia: Oficina de Joseph y Thomas de Orga, 1790.
} 
la Sociedad Bíblica (Knapp, 1899, I, pp. 230-238). Por todo ello, es probable que, dadas las fechas, tomara esta edición de Scío también como base para el Embéo, aunque este extremo no está demostrado.

El caló que encontramos en esta obra refleja gran heterogeneidad, tanto diatópica, debida a que los informantes procedían de varios lugares (Extremadura, Madrid, Andalucía y Valencia ${ }^{22}$ principalmente), como diastrática, puesto que Borrow no hace distinciones de nivel. No recoge aún invenciones de los aficionados ni voces germanescas, si bien ya encontramos algunas palabras creadas por el propio autor (Buzek, 2011, pp. 118-123), así como influencias del anglorromaní y del español (Krinková, 2015, pp. 46-48). Dietze (2012, pp. 76-77) señala algunas obras sobre el habla de los gitanos publicadas a finales del XVIII que pudieron servir de fuente para las traducciones del Embéo y de The Zincali, como las de Rüdiger ${ }^{23}$ y Grellmann ${ }^{24}$.

El Embéo tuvo cierta repercusión porque fue el primer libro escrito en un dialecto romaní. Pott lo citó frecuentemente en su obra Die Zigeuner in Europa und Asien ${ }^{25}$ y llamó la atención de investigadores de todo el continente (Knapp, 1899, I, pp. 253).

El segundo de los textos estudiados aparece al final de The Zincali y, como queda dicho, se trata de los versículos 1 a 28 del capítulo 21 del Evangelio de San Lucas. Es una traducción bilingüe en inglés y caló que recoge primero el pasaje del óbolo de la viuda (versículos 1 a 4) y, a continuación, gran parte del largo discurso escatológico de Jesús (versículos 5 a 28). Resulta un texto extraño porque no tiene unidad argumental ni presenta una o varias perícopas completas, sino que el discurso carece de los ocho versículos finales.

${ }^{22}$ Adiego (2008, p. 22) indica que ha encontrado varios valencianismos entre los vocablos del Embéo.

${ }^{23}$ Rüdiger, J. (1782). Von der Sprache und Herkunft der Zigeuner aus Indien. Leipzig: Rummer. ${ }^{24}$ Grellmann, H. (1783). Die Zigeuner. Ein historischer Versuch über die Lebensart und Verfassung, Sitten und Schicksahle dieses Volkes seit seiner Erscheinung in Europa und dessen Ursprung. Dessau: Buchhandlung der Gelehrten.

${ }^{25}$ Pott, A. (1844). Die Zigeuner in Europa und Asien. Ethnographisch-linguistische Untersuchung, vornehmlich ihrer Herkunft und Sprache. Erster Theil. Einleitung und Grammatik. Halle: Heynemann. 
La obra general en la que se inserta, The Zincali, presenta un contenido muy heterogéneo. Trata primero sobre los gitanos europeos y después se centra en los españoles. Detalla al respecto los usos y costumbres que Borrow conoció durante sus viajes por el país, así como las acusaciones más comunes contra los gitanos y las leyes dictadas para intentar regular su modo de vida. A todo ello se añade una serie de textos en caló, como poemas populares, proverbios, oraciones y un interesante vocabulario bilingüe, que fue la primera obra lexicográfica de envergadura dedicada al caló, si bien adolece de falta de rigor porque mezcla material de primera mano recopilado entre los gitanos con otro de origen dudoso. Por último, encontramos el texto evangélico que nos ocupa, cuyo caló es notablemente distinto al del Embéo, como luego se verá.

La última obra bíblica de Borrow apareció en Londres en 1872. Se trataba de la segunda edición de la traducción del Evangelio de San Lucas al caló, titulada Criscote e Majaró Lucas. La nueva versión tuvo su origen en la solicitud de una reimpresión del Embéo que el reverendo William Ireland Knapp formuló en 1870 a la Sociedad Bíblica. Esta transmite la petición a Borrow, el cual comienza a revisar su Embéo en abril de 1870 y termina dos meses después. Varios problemas debidos al carácter del autor retrasaron la publicación hasta diciembre de 1872 (Dietze, 2012, p. 75).

Lo cierto es que esta nueva versión presenta también bastantes diferencias con respecto a la traducción del Embéo, empezando por el propio título: Criscote e Majaró Lucas, chibado andré o Romano, ó chipé es Zincales de Sesé. El Evangelio según S. Lucas, traducido al Romaní, ó dialecto de los Gitanos de España. Asimismo, el fragmento estudiado no guarda gran parecido con el que aparece en The Zincali. No está claro en qué criterios se basó Borrow para elegir los cambios que introdujo, teniendo en cuenta que hacía décadas de su estancia en España y, que se sepa, no había tenido oportunidad de aprender mejor el caló, aunque quizá consultara algunas obras publicadas por los aficionados. Dietze (2012, p. 78) opina al respecto que pudo acceder 
en la biblioteca del Museo Británico a los repertorios españoles ya publicados en esa fecha ${ }^{26}$, entre ellos el de Quindalé (1867), así como a otros estudios europeos ${ }^{27}$. Sí sabemos que había viajado por Europa del Este en 1844 y que allí, como era su costumbre, se relacionó con los gitanos de la zona (Knapp, 1899, II, p. 12; Hancock, 1997, p. 202).

En vista de esta serie de versiones y revisiones, algunos autores ${ }^{28}$ plantean que el caló de Borrow era muy inestable porque probablemente no lo dominaba como él decía. Hancock (1997, pp. 200-206) le reprocha que mezclase dialectos distintos (caló, anglorromaní y variedades romaníes de Europa del Este, como el húngaro o el transilvano) y que no tuviera problema en inventarse palabras, pensando tal vez que sus lectores carecían de los conocimientos necesarios para percatarse de ello. Este autor crea un término para referirse al caló de Borrow: Borrowmani, al que define como un dialecto inventado que no era hablado por nadie y que aparece especialmente en el Criscote. Dietze (2012, p. 80), por su parte, defiende que en el Criscote al autor probablemente le interesaba más el purismo que ser entendido por los gitanos, especialmente tras las críticas de Pott.

El último texto que se ha sumado a la comparación es la edición bilingüe español-caló del Embéo que realizó el historiador capuchino Alberto

\footnotetext{
${ }^{26}$ Menciona en concreto la obra de Ramón Campuzano (1848. Orijen, uso y costumbres de los jitanos y diccionario de su dialecto. Con las voces equivalentes del castellano y sus definiciones. Madrid: Ediciones M. R. y Fonseca); el repertorio de D. A. de C. (1851. Diccionario del dialecto gitano. Origen y costumbres de los gitanos. Contiene más de 4500 voces con su correspondencia castellana y sus definiciones. Barcelona: Imprenta Hispana); y el diccionario de Augusto Jiménez (1846. Vocabulario del dialecto jitano, con cerca de 3000 palabras y una relación esacta del carácter, procedencia, usos costumbres, modo de vivir de esta jente en la mayor parte de las provincias de España, celebridad en las fiestas, nombres y apellidos más usuales, fisionomía y cuantos antecedentes se pueden tener de ellos, con varios rezos, cuentos, fábulas, versos, brindis, parte de la doctrina cristiana y ordenanza militar. Sevilla: Imprenta de D. J. M. Gutiérrez de Alba). También es posible, por la fecha, que conociera la ya mencionada obra de Trujillo.

${ }^{27}$ Destacan entre estos el ya aludido de Pott (vid. p. 9, n. 25) y el de Alexandros Paspati (1870. Études sur les Tchinghianés ou Bohémien de l'Empire Ottoman. Konstantinopel: Antoine Koroméla).

${ }^{28}$ Hancock, 1997, p. 211; Adiego y Martín, 2006, p. 21; Buzek, 2011, p. 118.
} 
González Caballero (1998), quien procuró ser fiel en general a la traducción de Borrow. Sin embargo, efectuó algunos cambios, corrigió erratas e incluso llegó a suprimir adiciones al texto original de Lucas (Buzek, 2011, pp. 231-233). Aunque reprochaba a Borrow que había gitanizado su segunda edición, el Criscote, eliminando aquellas palabras que habían aparecido en castellano en el Embéo, González Caballero decidió hacer lo mismo y sustituyó los términos españoles por otros calós. Se plantea así la cuestión de qué fuentes pudo haber consultado el sacerdote para efectuar dichos cambios, quien declara en el prólogo (1998, p. 9) que su edición obedece a un afán evangelizador, respondiendo al espíritu del Concilio Vaticano II, así como a un intento de recuperar el dialecto perdido de los gitanos españoles y rescatarlo de la situación de marginación. En ese sentido, esta obra tiene un gran valor testimonial y social, si bien seguramente su alcance fue reducido o nulo. Es un hecho que sus potenciales lectores ya no entendían ni entienden el caló, por más que les pueda agradar ver el texto en la lengua de sus antepasados.

\section{ESTUDIO DE LOS ESPAÑOLISMOS EN LAS TRES VERSIONES DEL TEX'TO}

Como queda dicho, encontramos en el Embéo bastantes voces en español que son sustituidas en las otras dos versiones por una palabra caló (o, al menos, que parece serlo). Así ocurre en el versículo 6 con demolida en Embéo (1837, p. 147), frente a demarabeá en The Zincali (1841, p. *130) y detechescada en Criscote (1872, p. 97). González Caballero sustituye este término por la expresión bucharada a bajiné (1998, p. 128), que aparece recogida en los diccionarios de Quindalé (1867, s. v. bucharar) y Pabanó (1915, s. v. bucharar) con el significado de 'arrojar, echar, lanzar'. Ni detechescada ni demarabeá ni sus respectivos infinitivos aparecen en los diccionarios mencionados, aunque sí consta marabear tanto en Quindalé (1867, s. $v$. marabear) como en Pabanó (1915, s. v. marabear) con el sentido de 'moler', 
por lo que demarabeá (incluso detechescada, sobre la raíz de techo) parece una invención al estilo de la afición. Tampoco Dietze recoge estos términos en su estudio.

\begin{tabular}{|c|c|c|c|c|}
\hline $\begin{array}{l}\text { Embéo (1837: } \\
\text { 147) }\end{array}$ & $\begin{array}{l}\text { The Zincali } \\
\left(1841:{ }^{*} 130\right)\end{array}$ & $\begin{array}{l}\text { Criscote } \\
\text { (1872: 97) }\end{array}$ & $\begin{array}{l}\text { González } \\
\text { Caballero } \\
\text { (1998: 128) }\end{array}$ & $\begin{array}{l}\text { Scío (1826: } \\
118)\end{array}$ \\
\hline $\begin{array}{l}\text { pur na sinará } \\
\text { mequelada } \\
\text { bar opré bar, } \\
\text { sos na sinará } \\
\text { demolida }\end{array}$ & $\begin{array}{l}\text { bus ne } \\
\text { muquelará } \\
\text { berrandáña } \\
\text { costuñé } \\
\text { berrandáña, } \\
\text { sos ne que- } \\
\text { sesa demara- } \\
\text { beá }\end{array}$ & $\begin{array}{l}\text { pur na sinará } \\
\text { mequelada } \\
\text { bar opré bar, } \\
\text { sos na sinará } \\
\text { detechescada }\end{array}$ & $\begin{array}{l}\text { pur na sinará } \\
\text { mequelada } \\
\text { bar opré bar, } \\
\text { sos na sinará } \\
\text { bucharada a } \\
\text { bajiné }\end{array}$ & $\begin{array}{l}\text { quando no } \\
\text { quedará } \\
\text { piedra sobre } \\
\text { piedra, que } \\
\text { no sea demo- } \\
\text { lida }\end{array}$ \\
\hline
\end{tabular}

En el versículo 7 aparece comenzáre en Embéo (1837, p. 147), frente a presimáre de The Zincali (1841, p. *130) y presimeláre de Criscote (1872, p. 97). En el versículo 28 vuelven a aparecer estos verbos, pero con la particularidad de que esta vez coinciden The Zincali (1841, p. *134) y Criscote (1872, p. 99) en la forma presimelaren, frente a la voz comenzaren en Embéo (1837, p. 150). González Caballero, por su parte, sustituye en el versículo 7 (1998, p. 128) la forma española por el verbo chitelare, mientras que en el versículo 28 (ibid., p. 132) usa también presimelaren, al igual que The Zincali y Criscote. Chitelar consta en Quindalé (1867, s. v. chitelar) con las acepciones de 'preparar, aviar, vestir, acopiar, fabricar' y en Pabanó (1915, s. v. chitelar) con las de 'aviar, preparar, vestir, fabricar, atesorar, envejecer'. Ninguno de estos sentidos es, pues, el que le da González Caballero, quien en su vocabulario adjunto a la edición de Embéo remite desde chitelar a chitar, término este último al que sí le da el sentido de 'comenzar' (1998, p. 163). Quindalé (1867, s. v. chitar), por su parte, ofrece las acepciones de 'colocar, plantar' para chitar, mientras que si buscamos 'comenzar' en Pabanó (1915, s. v. comenzar) encontramos también chitar, verbo que, a su vez, aparece en el listado inverso de esa 
misma obra con el sentido de 'arreglar, comenzar' (ibid., s. v. chitar). Por otro lado, presimar no aparece en los diccionarios españoles mencionados, pero presimelar sí, con el sentido de 'principiar, empezar', tanto en Quindalé (1867, s. v. presimelar) como en Pabanó (1915, s. v. presimelar). Por todo ello, parece que el presimáre de The Zincali en el versículo 7 es un error o una errata por presimeláre.

Según el estudio de Dietze (2012, p. 160), en el fragmento analizado por él, tanto el uso de comenzar como el de presimelar es escaso en Borrow, ya que aparecen una sola vez: el primero, en el capítulo 3, 23 de la versión de Embéo y el segundo, en el mismo pasaje de Criscote. Frente a estas formas, Dietze atestigua abundantemente chibarse (cinco veces en ambas versiones) $y$, en menor medida, chitelar (dos veces en cada versión, aunque en una de las ocasiones en que se usa en Criscote, por el sentido, parece una errata por chibelar 'vestirse'). Sin embargo, en el fragmento del capítulo 21, chibarse no aparece en Embéo ni en Criscote. Solo hallamos chibar en el versículo 4 en ambas versiones, en las que se adecua el sentido de 'echar'. De todo ello parece deducirse que Borrow usaba sistemáticamente comenzar en Embéo para 'comenzar', mientras que en las otras versiones empezó usando chibarse en los primeros capítulos y después prefirió presimelar. Chibarse parece un calco del verbo echarse que se usa en español en las perífrasis incoativas.

\begin{tabular}{|c|c|c|c|c|}
\hline $\begin{array}{l}\text { Embéo (1837: } \\
\text { 147) }\end{array}$ & $\begin{array}{l}\text { The Zincali } \\
\left(1841:{ }^{*} 130\right)\end{array}$ & $\begin{array}{l}\text { Criscote } \\
\text { (1872: 97) }\end{array}$ & $\begin{array}{l}\text { González } \\
\text { Caballero } \\
\text { (1998: 128) }\end{array}$ & $\begin{array}{l}\text { Scío (1826: } \\
118)\end{array}$ \\
\hline $\begin{array}{l}\text { Y le pucha- } \\
\text { báron, y } \\
\text { penáron: } \\
\text { ¿Duquendio, } \\
\text { pur sinará } \\
\text { ocono? y } \\
\text { que sima- } \\
\text { che sinará, } \\
\text { pur ocono } \\
\text { comenzáre á } \\
\text { sinar? }\end{array}$ & $\begin{array}{l}\text { Y le pru- } \\
\text { cháron y } \\
\text { pendáron: } \\
\text { Docurdó, } \\
\text { bus quesa } \\
\text { ondoba? Y } \\
\text { sos simachi } \\
\text { abicará bus } \\
\text { ondoba presi- } \\
\text { máre? }\end{array}$ & $\begin{array}{l}\text { Y le pucha- } \\
\text { báron, y } \\
\text { penáron: } \\
\text { ¿Docurdo, pur } \\
\text { sinará ocono? } \\
\text { y que sima- } \\
\text { che sinará, } \\
\text { pur ocono } \\
\text { presimeláre á } \\
\text { sinar? }\end{array}$ & $\begin{array}{l}\text { Le puche- } \\
\text { baron: } \\
\text { "Duquendio, } \\
\text { ¿pur sinará } \\
\text { ocono? y } \\
\text { ¿que simache } \\
\text { sinará pur } \\
\text { ocono chite- } \\
\text { lare a sinar? }\end{array}$ & $\begin{array}{l}\text { Y le pregun- } \\
\text { táron, y dixé- } \\
\text { ron: ¿Maestro, } \\
\text { quándo será } \\
\text { esto? ¿y qué } \\
\text { señal habrá, } \\
\text { quando esto } \\
\text { comenzáre á } \\
\text { ser? }\end{array}$ \\
\hline
\end{tabular}


El adverbio entonces aparece en el versículo 10 en Embéo (1837, p. 148), frente a la forma oclinde que hallamos en The Zincali (1841, p. *132) y Criscote (1872, p. 97). González Caballero mantiene el adverbio en español (1998, p. 130). Esta misma distribución de los términos entonces y oclinde se produce en los versículos 20 (1837, p.149; 1841, p. *132; 1872, p. 98; 1998, p. 130); 21 (1837, p. 149; 1841, p. *132; 1872, p. 98; 1998, p. 130); y 27 (1837, p. $150 ; 1841$, p. ${ }^{* 134 ;} 1872$, p. $99 ; 1998$, p. 132). Ninguna de las dos formas aparece en los diccionarios de Quindalé y Pabanó. Por su parte, Dietze (2012, p. 156) registra ambas voces una sola vez, repitiéndose el esquema: mientras Embéo presenta entonces, Criscote muestra oclinde. Señala también (ibid., p. 143) que no se pudo encontrar el origen o la formación de esta palabra.

Asimismo, hallamos en este versículo 10 la preposición contra en tres de las versiones: Embéo (1837, p. 148), Criscote (1872, p. 97) y González Caballero (1998, p. 130), mientras que en The Zincali Borrow usa la voz sartra (1841, p. *132). Este término, que no consta en Quindalé ni en Pabanó, parece una nueva invención formada como calco de la preposición española contra, segmentada como con-tra, ya que sar significa 'con' según Quindalé (1867, s. v. sar). En el estudio de Dietze (2012, p. 174), contra se recoge dos veces tanto en Embéo como en Criscote y no aparece sartra.

\begin{tabular}{|c|c|c|c|c|}
\hline $\begin{array}{l}\text { Embéo (1837: } \\
\text { 148) }\end{array}$ & $\begin{array}{l}\text { The Zincali } \\
\text { (1841: *132) }\end{array}$ & $\begin{array}{l}\text { Criscote } \\
\text { (1872: 97) }\end{array}$ & $\begin{array}{l}\text { González Caba- } \\
\text { llero (1998: 130) }\end{array}$ & $\begin{array}{l}\text { Scío (1826: } \\
118)\end{array}$ \\
\hline $\begin{array}{l}\text { Entonces les } \\
\text { penaba: Se } \\
\text { ardiñará sueti } \\
\text { contra sueti, } \\
\text { y chim contra } \\
\text { chim }\end{array}$ & $\begin{array}{l}\text { Oclinde les } \\
\text { pendaba: } \\
\text { se sustinará } \\
\text { suéste sartra } \\
\text { suéste, y } \\
\text { sichén sartra } \\
\text { sichén }\end{array}$ & $\begin{array}{l}\text { Oclinde les } \\
\text { penaba: Se } \\
\text { surdinará } \\
\text { sueti contra } \\
\text { sueti, ta } \\
\text { clajita contra } \\
\text { clajita }\end{array}$ & $\begin{array}{l}\text { Entonces les } \\
\text { penaba: "Se ardi- } \\
\text { ñará sueti contra } \\
\text { sueti y chim } \\
\text { contra chim }\end{array}$ & $\begin{array}{l}\text { Estónces les } \\
\text { decia: Se } \\
\text { levantará } \\
\text { gente con- } \\
\text { tra gente, y } \\
\text { reyno con- } \\
\text { tra reyno }\end{array}$ \\
\hline
\end{tabular}

TABLA 3: versículo 10

La palabra espantosas del versículo 11 en Embéo (1837, p. 148) es sustituida por espajuis en The Zincali (1841, p. *132) y miratosas en Criscote (1872, p. 97). Espajuis parece relacionada con el término espajú, que recogen 
Quindalé (1867, s. v. espajú) y Pabanó (1915, s. v. espajú) como 'espanto, horror', pero miratosas no aparece, ni consta ningún término relacionado. González Caballero (1998, p. 130) usa berrochías en su lugar, voz que no recogen ni Quindalé ni Pabanó como adjetivo, aunque sí encontramos en ambos diccionarios la entrada berrochí como sustantivo con el sentido de 'horror' (Quindalé, 1867, s. v. berrochi; Pabanó, 1915, s. v. berrochí). Por su parte, en Dietze (2012, p. 128) se atestigua solo el verbo espajuaban, 'se pasmaban' según la versión de Scío.

\begin{tabular}{|c|c|c|c|c|}
\hline $\begin{array}{l}\text { Embéo (1837: } \\
\text { 148) }\end{array}$ & $\begin{array}{l}\text { The Zincali } \\
(1841: * 132)\end{array}$ & $\begin{array}{l}\text { Criscote } \\
\text { (1872: 98) }\end{array}$ & $\begin{array}{l}\text { González Caba- } \\
\text { llero (1998: 130) }\end{array}$ & $\begin{array}{l}\text { Scío (1826: } \\
118)\end{array}$ \\
\hline $\begin{array}{l}\text { y sinará } \\
\text { buchias } \\
\text { espantosas, y } \\
\text { barias sima- } \\
\text { ches e Charos }\end{array}$ & $\begin{array}{l}\text { y abicará } \\
\text { buchenerés } \\
\text { espajuis y } \\
\text { bareles sima- } \\
\text { chis de otárpe }\end{array}$ & $\begin{array}{l}\text { y sinará } \\
\text { buchías } \\
\text { miratosas, } \\
\text { y barias } \\
\text { simaches e } \\
\text { Charos }\end{array}$ & $\begin{array}{l}\text { y sinará buchías } \\
\text { berrochias, y } \\
\text { barias siman- } \\
\text { ches e charos }\end{array}$ & $\begin{array}{l}\text { y habrá cosas } \\
\text { espantosas, y } \\
\text { grandes seña- } \\
\text { les del Cielo }\end{array}$ \\
\hline
\end{tabular}

TABLA 4: versículo 11

El caso del verbo resistir, que aparece en el versículo 15 en Embéo (1837, p. 148), es llamativo, porque Borrow lo conserva en The Zincali como resistír (1841, p. *132) y lo sustituye por la expresión querelar jeró en Criscote (1872, p. 98), que en Quindalé se traduce como 'hacer frente' (1867, s. v. jeró) pero en Pabanó no consta. Parece un calco del español confeccionado sobre la unión de querelar 'hacer' (Quindalé, 1867, s. v. querelar) y jeró 'cabeza, cumbre' (ibid., s. v. jeró). Además, Criscote cambia el orden en el que figuran las palabras del versículo 15 en el resto de las versiones: frente a la secuencia "no podrán resistir ni contradecir», Criscote presenta "no podrán contradecir ni hacer frente». Por su parte, en González Caballero (1998, p. 130) hallamos otra voz distinta para 'resistir': chiguatar, que se recoge en Pabanó (1915, s. $v$. chiguatar) con el significado de 'aguantar, detener, sujetar', pero no en Quindalé. 
En Dietze no consta la expresión querelar jeró ni los términos resistir ni chiguatar.

\begin{tabular}{|c|c|c|c|c|}
\hline $\begin{array}{l}\text { Embéo (1837: } \\
\text { 148) }\end{array}$ & $\begin{array}{l}\text { The Zincali } \\
(1841: * 132)\end{array}$ & $\begin{array}{l}\text { Criscote } \\
\text { (1872: 98) }\end{array}$ & $\begin{array}{l}\text { González } \\
\text { Caballero } \\
\text { (1998: 130) }\end{array}$ & $\begin{array}{l}\text { Scío (1826: } \\
118)\end{array}$ \\
\hline $\begin{array}{l}\text { Presas menda } \\
\text { diñaré sangue } \\
\text { mui y chane- } \\
\text { leria, al que } \\
\text { n'astisarelarán } \\
\text { resistir, ni } \\
\text { contrapenar } \\
\text { sares jires } \\
\text { daschmanu- } \\
\text { ces }\end{array}$ & $\begin{array}{l}\text { persos man } \\
\text { os diñaré } \\
\text { rotuñi y } \\
\text { chanár, la sos } \\
\text { ne asislarán } \\
\text { resistír ne } \\
\text { sartra pendar } \\
\text { saros bros } \\
\text { enormes. }\end{array}$ & $\begin{array}{l}\text { Presas menda } \\
\text { diñaré sangue } \\
\text { mui y chane- } \\
\text { leria, al que } \\
\text { n'astisarelarán } \\
\text { contrapenar, } \\
\text { ni querelar } \\
\text { jeró sares jires } \\
\text { daschmanu- } \\
\text { ces }\end{array}$ & $\begin{array}{l}\text { presas menda } \\
\text { diñaré sangue } \\
\text { mui y chane- } \\
\text { lería al que } \\
\text { n'astisarelarán } \\
\text { chiguatar ni } \\
\text { contrapenar } \\
\text { sares jires } \\
\text { daschmanu- } \\
\text { ces }\end{array}$ & $\begin{array}{l}\text { Porque yo os } \\
\text { daré boca y } \\
\text { saber, al que } \\
\text { no podrán } \\
\text { resistir, ni } \\
\text { contradecir } \\
\text { todos vues- } \\
\text { tros adversa- } \\
\text { rios. }\end{array}$ \\
\hline
\end{tabular}

En el versículo 16 aparece en Embéo entregados (1837, p. 148), frente a binados en Criscote (1872, p. 98) y enregaos en The Zincali (1841, p. *132). Este último término figura también en el versículo 12 en The Zincali (ibid., p. *132): enregandoós, y parece una invención hecha sobre el calco del verbo entregar en español, segmentado de forma no etimológica como entre-gar. González Caballero usa la voz entregisarados (1998, p. 130), que aparece tanto en Quindalé (1867, s. v. entregisarar) como en Pabanó (1915, s. v. entregisarar) con los significados de 'entregar, deponer' en el primero y 'dar, entregar' en el segundo. El verbo binar de Criscote (1872, p. 98) se traduce en Quindalé (1867, s. v. binar) y en Pabanó (1915, s.v. vender) como 'vender'.

En Dietze no aparece entregar ni enregar. La preposición enré sí se atestigua en varios pasajes en su estudio y explica (2012, p. 139) que puede ser una invención ( $p$ seudo-caló según su terminología) porque su origen es oscuro. 


\begin{tabular}{|c|c|c|c|c|}
\hline $\begin{array}{l}\text { Embéo (1837: } \\
\text { 148) }\end{array}$ & $\begin{array}{l}\text { The Zincali } \\
\text { (1841: *132) }\end{array}$ & $\begin{array}{l}\text { Criscote } \\
\text { (1872: 98) }\end{array}$ & $\begin{array}{l}\text { González } \\
\text { Caballero } \\
\text { (1998: 130) }\end{array}$ & $\begin{array}{l}\text { Scío (1826: } \\
\text { 118) }\end{array}$ \\
\hline $\begin{array}{l}\text { Y sinareis } \\
\text { entregados de } \\
\text { jires batuces }\end{array}$ & $\begin{array}{l}\text { Y quesaréis } \\
\text { enregaos de } \\
\text { bros bátos }\end{array}$ & $\begin{array}{l}\text { Y sinareis } \\
\text { binados de } \\
\text { jires batuces }\end{array}$ & $\begin{array}{l}\text { Sinaréis entre- } \\
\text { gisarados de } \\
\text { jires batuces }\end{array}$ & $\begin{array}{l}\text { Y seréis } \\
\text { entregados } \\
\text { de vuestros } \\
\text { padres }\end{array}$ \\
\hline
\end{tabular}

TABLA 6: versículo 16

En Embéo consta el futuro aborrecerán en el versículo 17 (1837, p. 148), al igual que en González Caballero (1998, p. 130), pero es sustituido por solajarán en Criscote (1872, p. 98) y cangelarán en The Zincali (1841, p. *132). Solajar aparece como 'blasfemar, maldecir' en Quindalé (1867, s. v. solajar) y Pabanó (1915, s. v. solajar), mientras que canguelar se recoge como 'temer, turbar, recelar' en dichos repertorios (Quindalé 1867, s. v. canguelar; Pabanó 1915, s. v. canguelar). En Dietze (2012, p. 171) aparece el verbo aborrecer una vez en Embéo con la forma aborrecieren, mientras que en Criscote encontramos na-camelaren.

\begin{tabular}{|l|l|l|l|l|}
\hline $\begin{array}{l}\text { Embéo }(1837: \\
\text { 148) }\end{array}$ & $\begin{array}{l}\text { The Zincali } \\
\left(1841:{ }^{* 132)}\right.\end{array}$ & $\begin{array}{l}\text { Criscote } \\
(1872: 98)\end{array}$ & $\begin{array}{l}\text { González } \\
\text { Caballero } \\
(1998: 130)\end{array}$ & $\begin{array}{l}\text { Scío }(1826: \\
118)\end{array}$ \\
\hline $\begin{array}{l}\text { Y sares abo- } \\
\text { rrecerán á } \\
\begin{array}{l}\text { sangue pre } \\
\text { minrio nao }\end{array}\end{array}$ & $\begin{array}{l}\text { y os cangela- } \\
\text { rán saros per } \\
\text { men acnao }\end{array}$ & $\begin{array}{l}\text { Y sares } \\
\text { solajarán á } \\
\text { sangue pre } \\
\text { minrio nao }\end{array}$ & $\begin{array}{l}\text { y sares abo- } \\
\text { rrecerán a } \\
\text { sangue pre } \\
\text { minrio nao }\end{array}$ & $\begin{array}{l}\text { Y os aborre- } \\
\text { cerán todos } \\
\text { por mi nom- } \\
\text { bre }\end{array}$ \\
\hline
\end{tabular}

TABLA 7: versículo 17

El sustantivo paciencia del versículo 19 en Embéo (1837, p. 149) es sustituido por la voz opachirimá en The Zincali (1841, p. *132) y por orpachirima en Criscote (1872, p. 98). En González Caballero encontramos también orpachirima (1998, p. 130), cuyo significado en Quindalé (1867, s. v. orpachirima) es 'paciencia, mansedumbre' y en Pabanó (1915, s. v. orpachirima) 'calma, mansedumbre, paciencia'. Dietze no atestigua ni paciencia ni opachirima, pero sí 
orpachirima una vez en Embéo y Criscote (2012, p. 181), por lo que la forma $\sin <\mathrm{r}>$ de The Zincali puede tratarse de una errata, tal vez de imprenta.

\begin{tabular}{|c|c|c|c|c|}
\hline $\begin{array}{l}\text { Embéo (1837: } \\
\text { 149) }\end{array}$ & $\begin{array}{l}\text { The Zincali } \\
\text { (1841: *132) }\end{array}$ & $\begin{array}{l}\text { Criscote } \\
\text { (1872: } 98)\end{array}$ & $\begin{array}{l}\text { González Caba- } \\
\text { llero (1998: 98) }\end{array}$ & $\begin{array}{l}\text { Scío (1826: } \\
118)\end{array}$ \\
\hline $\begin{array}{l}\text { Sat jiri } \\
\text { paciencia lis- } \\
\text { trabareis jirias } \\
\text { ochias }\end{array}$ & $\begin{array}{l}\text { Sar bras } \\
\text { opachirimá } \\
\text { avelaréis } \\
\text { bras orchis }\end{array}$ & $\begin{array}{l}\text { Sar jiri } \\
\text { orpachirima } \\
\text { listrabareis } \\
\text { jirias ochías }\end{array}$ & $\begin{array}{l}\text { Sat jires orpa- } \\
\text { chirima lis- } \\
\text { trabaréis jirias } \\
\text { ochías }\end{array}$ & $\begin{array}{l}\text { Con vuestra } \\
\text { paciencia } \\
\text { poseeréis } \\
\text { vuestras almas }\end{array}$ \\
\hline
\end{tabular}

La expresión española en medio de, que aparece en el versículo 21 en Embéo (1837, p. 149) y en González Caballero (1998, p. 130), se sustituye por on macara de en The Zincali (1841, p. *132) y por en majara de en Criscote (1872, p. 98). Quindalé (1867, s. v. macara) ofrece la traducción 'mitad, medio' y Pabanó (1915, s. v. mitad) da el sentido de 'mitad' a macará, pero en el diccionario inverso indica que macára es 'mitad' y macará 'plaza'. Majara no aparece en estos repertorios y Dietze no atestigua ni en medio de ni on macara de.

\begin{tabular}{|c|c|c|c|c|}
\hline $\begin{array}{l}\text { Embéo (1837: } \\
\text { 149) }\end{array}$ & $\begin{array}{l}\text { The Zincali } \\
\left(1841:{ }^{*} 132\right)\end{array}$ & $\begin{array}{l}\text { Criscote (1872: } \\
98)\end{array}$ & $\begin{array}{l}\text { González } \\
\text { Caballero } \\
\text { (1998: 130) }\end{array}$ & $\begin{array}{l}\text { Scío (1826: } \\
\text { 118-119) }\end{array}$ \\
\hline $\begin{array}{l}\text { Entonces } \\
\text { junos sos } \\
\text { sinelan andré } \\
\text { la Judéa, } \\
\text { najalelen á os } \\
\text { bures: y junos } \\
\text { en medio de } \\
\text { siró se sico- } \\
\text { belen abrí }\end{array}$ & $\begin{array}{l}\text { oclinde los } \\
\text { soscabelan } \\
\text { on la Chutéa, } \\
\text { chapésguen } \\
\text { á los torbejé- } \\
\text { lis; y los que } \\
\text { on macara } \\
\text { de ondolaya, } \\
\text { niquillense }\end{array}$ & $\begin{array}{l}\text { Oclinde ondo- } \\
\text { les sos sinelan } \\
\text { andré la } \\
\text { Judéa, najile- } \\
\text { len á os bures: } \\
\text { y ondoles en } \\
\text { majara de lati } \\
\text { se sicobelen } \\
\text { abrí }\end{array}$ & $\begin{array}{l}\text { Entonces } \\
\text { junos sos } \\
\text { sinelas andré } \\
\text { la Judea, } \\
\text { najalelen a os } \\
\text { bures, y junos } \\
\text { en medio de } \\
\text { siro se sicobe- } \\
\text { len abrí }\end{array}$ & $\begin{array}{l}\text { Entónces los } \\
\text { que están } \\
\text { en la Judéa, } \\
\text { huyan á los } \\
\text { montes: y los } \\
\text { que en medio } \\
\text { de ella, sál- } \\
\text { ganse }\end{array}$ \\
\hline
\end{tabular}

En el versículo 22 encontramos el sustantivo venganza en Embéo (1837, p. 149), mientras que en The Zincali aparece abilláza (1841, p. *132) y curelo pre crejete en Criscote (1872, p. 98). En González Caballero hallamos la voz corrupén (1998, p. 130), que no aparece en los diccionarios mencionados, mientras que tanto Quindalé (1867, s. v. curelo y curelar) como Pabanó (1915, 
s. v. curelo) sí recogen curelo como 'negocio, ocupación, afán', curelar como 'castigar, penar, trabajar' (ibid., s. v. curelar) y crejete como 'pecado' (ibid., s. v. crejete). En Dietze no consta ni venganza ni abilláza.

\begin{tabular}{|c|c|c|c|c|}
\hline $\begin{array}{l}\text { Embéo (1837: } \\
\text { 149) }\end{array}$ & $\begin{array}{l}\text { The Zincali } \\
(1841: * 132)\end{array}$ & $\begin{array}{l}\text { Criscote } \\
\text { (1872: 98) }\end{array}$ & $\begin{array}{l}\text { González } \\
\text { Caballero } \\
\text { (1998: 130) }\end{array}$ & $\begin{array}{l}\text { Scío (1826: } \\
119)\end{array}$ \\
\hline $\begin{array}{l}\text { Presas oco- } \\
\text { nas sinelan } \\
\text { chibeses de } \\
\text { venganza }\end{array}$ & $\begin{array}{l}\text { persos } \\
\text { ondoba sen } \\
\text { chibéles de } \\
\text { Abilláza }\end{array}$ & $\begin{array}{l}\text { Presas oconas } \\
\text { sinelan chibe- } \\
\text { ses de curelo } \\
\text { pre crejete }\end{array}$ & $\begin{array}{l}\text { presas oco- } \\
\text { nas sinelan } \\
\text { chibeses de } \\
\text { corrupén }\end{array}$ & $\begin{array}{l}\text { Porque estos } \\
\text { son dias de } \\
\text { venganza }\end{array}$ \\
\hline
\end{tabular}

El sustantivo apretura, usado con el sentido de 'calamidad' en el versículo 23 de Embéo (1837, p. 149), se sustituye por quichartúra en The Zincali (1841, p. *134) y quichardinipen en Criscote (1872, p. 99). González Caballero usa la voz berrochi (1998, p. 130), definido como 'horror' en Quindalé (1867, s. v. berrochi) y 'horror, aversión' en Pabanó (1915, s. v. berrochi). Ni quichartúra ni quichardinipén aparecen en esos diccionarios, aunque sí recogen voces parecidas como quichardila 'mancha' (Quindalé, 1867, s. v. quichardila; Pabanó, 1915, s. v. quichardila) o quichardilar 'manchar, mancha' (Quindalé, 1867, s. v. quichardilar; Pabanó, 1915, s. v. quichardilar). La terminación -tura que usa Borrow en la palabra de The Zincali, quichartúra, parece remitir a una invención al estilo de la afición, pero no está claro qué raíz utilizó. Ninguno de esos términos aparece en Dietze.

En este mismo versículo 23 de Embéo (1837, p. 149) se recoge la voz española ira en la expresión sinará [...] ira para ocona sueti "habrá [...] ira para este pueblo» (Scío, 1826, p. 119), desaparece en las otras dos versiones de Borrow. Por un lado, en The Zincali (1841, p. 134) encontramos guillará pa andoba Gao. Según Quindalé guillar significa 'ir aprisa' (1867, s. v. guillar), así que parece que Borrow no entendió la traducción de Scío «e ira para éste pueblo", que presenta una elipsis del verbo 'habrá', sino que confundió el sustantivo ira con el futuro del verbo ir y tradujo «e irá contra este pueblo». 
Por otro lado, en Criscote (1872, p. 99) encontramos tornasibá pa ocona sueti, cuyo sentido tampoco está claro. La forma tornasibá podría ser una errata o confusión por tornasibará, en futuro, que es el tiempo adecuado en ese enunciado, pero Quindalé no recoge ese supuesto verbo tornasibar. Sin embargo, sí da cuenta del sustantivo tornaciba 'rabia' $(1867$, s. v. tornaciba), mientras que en Pabanó tornacibá aparece traducido como 'hidrofobia, rabia' (1915, s. v. tornacibá) y tornacibé como 'cólera, coraje, ira' (ibid., s. v. tornacibé), con lo cual es posible que Borrow se hubiera percatado de su error en esta última versión y lo hubiese corregido intentando usar un término que significase 'ira', si bien parece que atestigua un caso de seseo con la confusión entre las grafías $<\mathrm{c}>\mathrm{y}<\mathrm{s}>$.

González Caballero, por su parte, usa en este contexto otro término, ajurjuñi (1998, p. 130), que se traduce por 'soberbia, cólera' en Quindalé (1867, s. v. ajurjuñi, arjujurjuñi) y que, como adjetivo, se traduce por 'airada, soberbia, colérica’ en Quindalé (1867, s. v. ajurjunó (sic), uñí) y Pabanó (1915, s. v. ajurjunó (sic), uñî). Según Pabanó, 'cólera' es ajurjuñé (ibid., s. v. ajurjuñé). Por otro lado, en el estudio de Dietze no aparece esta última palabra, pero sí consta ira en el Embéo (2012, p. 158), mientras que en Criscote vemos tornasibá en el mismo contexto. Este último término aparece también en otras tres ocasiones en Criscote, aunque sin tilde: en el capítulo 3, frente a sana / saña tanto en Embéo como en Scío (Dietze, 2012, p. 158); y en el capítulo 7, donde vemos buros 'tempestad' en Embéo y tempestad en Scío (ibid., p. 182), al igual que en el siguiente versículo (ibid., p. 182).

\begin{tabular}{|c|c|c|c|c|}
\hline $\begin{array}{l}\text { Embéo } \\
\text { (1837: 149) }\end{array}$ & $\begin{array}{l}\text { The Zincali } \\
\text { (1841: *134) }\end{array}$ & $\begin{array}{l}\text { Criscote (1872: } \\
99)\end{array}$ & $\begin{array}{l}\text { González } \\
\text { Caballero } \\
\text { (1998: 130) }\end{array}$ & $\begin{array}{l}\text { Scío (1826: } \\
119)\end{array}$ \\
\hline $\begin{array}{l}\text { Presas } \\
\text { sinará bari } \\
\text { apretura } \\
\text { opré a pu, } \\
\text { y ira para } \\
\text { ocona sueti }\end{array}$ & $\begin{array}{l}\text { persos abicará } \\
\text { bar quichartúra } \\
\text { costuñe la chen } \\
\text { e guillará pa } \\
\text { andoba Gao }\end{array}$ & $\begin{array}{l}\text { Presas sinará } \\
\text { bari quichardi- } \\
\text { nipen opré a } \\
\text { pu, y torna- } \\
\text { sibá pa ocona } \\
\text { sueti }\end{array}$ & $\begin{array}{l}\text { "Sinará bari } \\
\text { berrochi } \\
\text { opré a pu, y } \\
\text { ajurjuñi pa } \\
\text { ocona sueti }\end{array}$ & $\begin{array}{l}\text { porque habrá } \\
\text { grande apre- } \\
\text { tura sobre } \\
\text { la tierra, é } \\
\text { ira para éste } \\
\text { pueblo }\end{array}$ \\
\hline
\end{tabular}

TABLA 11: versículo 23 
La palabra española filo consta en el versículo 24 de Embéo (1837, p. 149), frente a las voces surabi de The Zincali (1841, p. *134) y mui de Criscote (1872, p. 99). González Caballero sustituye filo por chirdé (1998, p. 130), que aparece en Quindalé (1867, s. v. chirdé) y Pabanó (1915, s. v. chirdé) con la acepción de 'corte, filo'. Surabi no está en los repertorios mencionados y muí tiene en ellos la acepción de 'boca' (Quindalé, 1867, s. v. muí; Pabanó, $1915, s . v$. muí), que no parece convenir al contexto. En Dietze no se recoge la forma filo.

\begin{tabular}{|c|c|c|c|c|}
\hline $\begin{array}{l}\text { Embéo (1837: } \\
\text { 149) }\end{array}$ & $\begin{array}{l}\text { The Zincali } \\
(1841: * 134)\end{array}$ & $\begin{array}{l}\text { Criscote } \\
\text { (1872: 99) }\end{array}$ & $\begin{array}{l}\text { González } \\
\text { Caballero } \\
\text { (1998: 130) }\end{array}$ & $\begin{array}{l}\text { Scío (1926: } \\
119)\end{array}$ \\
\hline $\begin{array}{l}\text { Y perarán á } \\
\text { filo e estuche: } \\
\text { y sinarán } \\
\text { lliguerados } \\
\text { utildes á sares } \\
\text { os chimes }\end{array}$ & $\begin{array}{l}\text { y petrarán } \\
\text { á surabi de } \\
\text { janrró; y que- } \\
\text { san legeraos } \\
\text { sinastros } \\
\text { á sarés las } \\
\text { chénes }\end{array}$ & $\begin{array}{l}\text { Y perarán á } \\
\text { la mui e estu- } \\
\text { che: y sinarán } \\
\text { lliguerados } \\
\text { utildes á sares } \\
\text { os chimes }\end{array}$ & $\begin{array}{l}\text { y perarán a } \\
\text { chirdé e estu- } \\
\text { che, y sinarán } \\
\text { lliguerados } \\
\text { utildes a sares } \\
\text { os chimes. }\end{array}$ & $\begin{array}{l}\text { Y caerán } \\
\text { á filo de } \\
\text { espada, y } \\
\text { serán llevados } \\
\text { en cautiverio } \\
\text { á todas las } \\
\text { naciones }\end{array}$ \\
\hline
\end{tabular}

TABLA 12: versículo 24 ( $1^{a}$ parte)

En Embéo encontramos en el versículo 24 la forma hollada (1837, p. 149), frente a omaná en The Zincali (1841, p. *134) y la expresión atelis os pindrés 'bajo ${ }^{29}$ los pies' en Criscote (1872, p. 99). González Caballero usa hollandada (1998, p. 130), que no aparece ni en Quindalé ni en Pabanó. En cuanto a omaná, tanto Quindalé (1867, s. v. omán) como Pabanó (1915, s.v. omán) recogen el vocablo omán con las acepciones de 'hoyo, hondura, hueco, cavidad, concavidad'. En Dietze (2012, p. 180) hollada aparece en Embéo en el capítulo 8, al igual que en Scío, frente a la expresión pirada opré en Criscote.

29 Traducción basada en el significado que el propio Borrow ofrece del término atelis en el vocabulario de The Zincali (1841, II, p. *6), ya que dicho término no aparece en los diccionarios consultados. 


\begin{tabular}{|c|c|c|c|c|}
\hline $\begin{array}{l}\text { Embéo (1837: } \\
\text { 149) }\end{array}$ & $\begin{array}{l}\text { The Zincali } \\
\text { (1841: *134) }\end{array}$ & $\begin{array}{l}\text { Criscote } \\
\text { (1872: 99) }\end{array}$ & $\begin{array}{l}\text { González } \\
\text { Caballero } \\
\text { (1998: 130) }\end{array}$ & $\begin{array}{l}\text { Scío (1926: } \\
\text { 119) }\end{array}$ \\
\hline $\begin{array}{l}\text { y Jerusalém } \\
\text { sinará bollada } \\
\text { de los Bus- } \\
\text { nés: disde } \\
\text { que se perele } \\
\text { o chiros es } \\
\text { Busnes. }\end{array}$ & $\begin{array}{l}\text { y Jerusalén } \\
\text { quesá omaná } \\
\text { de los sues- } \\
\text { tíles, sasta sos } \\
\text { quejesen los } \\
\text { chirós de las } \\
\text { sichenes; }\end{array}$ & $\begin{array}{l}\text { y Jerusalém } \\
\text { sinará atelis } \\
\text { os pindrés de } \\
\text { los Busnes: } \\
\text { disde que } \\
\text { se perele } \\
\text { o chiros es } \\
\text { Busnes. }\end{array}$ & $\begin{array}{l}\text { y Jerusalén } \\
\text { sinará hollan- } \\
\text { dada de los } \\
\text { busnés, disde } \\
\text { que se perele } \\
\text { o chinos es } \\
\text { busnés. }\end{array}$ & $\begin{array}{l}\text { y Jerusalém } \\
\text { será hollada } \\
\text { de los Genti- } \\
\text { les: hasta que } \\
\text { se cumplan } \\
\text { los tiempos } \\
\text { de las nacio- } \\
\text { nes. }\end{array}$ \\
\hline
\end{tabular}

TABLA 13: versículo 24 ( $2^{a}$ parte)

El sustantivo confusion en el versículo 25 de Embéo (1837, p. 150) se sustituye por dán 'estruendo' de The Zincali (1841, p. *134) y por la expresión en perpléjo en Criscote (1872, p. 99). González Caballero usa la voz darañalí (1998, p. 130), que Quindalé (1867, s. v. darañalí) y Pabanó (1915, s. v. daranalí) recogen con el sentido de 'pasmo, conmoción, temor'. Dan no aparece y perplejó consta con el sentido de 'susto' en Quindalé (1867, s.v. perplejó), mientras que Pabanó no lo referencia. Estas formas (confusion, dán, perpléjo y darañalí) no aparecen en el estudio de Dietze.

\begin{tabular}{|c|c|c|c|c|}
\hline $\begin{array}{l}\text { Embéo (1837: } \\
\text { 150) }\end{array}$ & $\begin{array}{l}\text { The Zincali } \\
\text { (1841: *134) }\end{array}$ & $\begin{array}{l}\text { Criscote } \\
\text { (1872: 99) }\end{array}$ & $\begin{array}{l}\text { González } \\
\text { Caballero } \\
\text { (1998: 130) }\end{array}$ & $\begin{array}{l}\text { Scío (1926: } \\
119)\end{array}$ \\
\hline $\begin{array}{l}\text { y andré la } \\
\text { pu tráqui es } \\
\text { manuces pre } \\
\text { a confusion } \\
\text { sos querelara } \\
\text { a chumas e } \\
\text { moros, y de } \\
\text { sus panias. }\end{array}$ & $\begin{array}{l}\text { y on la chen } \\
\text { chalabeó on } \\
\text { la suéste per } \\
\text { or dán sos } \\
\text { bausalará la } \\
\text { loria y des- } \\
\text { querós gulas; }\end{array}$ & $\begin{array}{l}\text { y andré la } \\
\text { pu dajiralo } \\
\text { de sueti en } \\
\text { perpléjo; o } \\
\text { Maçulotende } \\
\text { y as gulas } \\
\text { catabranando; }\end{array}$ & $\begin{array}{l}\text { y andré la } \\
\text { pu traqui es } \\
\text { manuces pre } \\
\text { a darañalí } \\
\text { sos querelará } \\
\text { a chumas e } \\
\text { moros y de } \\
\text { sus panías, }\end{array}$ & $\begin{array}{l}\text { y en la tierra } \\
\text { consterna- } \\
\text { cion de las } \\
\text { gentes por } \\
\text { la confusion } \\
\text { que causará } \\
\text { el ruido del } \\
\text { mar, y de sus } \\
\text { ondas: }\end{array}$ \\
\hline
\end{tabular}

TABLA 14: versículo 25

Por último, en el versículo 26 hallamos la forma conmovidas en Embéo (1837, p. 150), pero en The Zincali (1841, p. *134) aparece sar-chalabeaos y en Criscote, chalabeadas (1872, p. 99). González Caballero también usa 
chalabeadas (1998, p. 132), verbo que aparece en Quindalé (1867, s. v. chalabear) y Pabanó (1915, s. v. chalabear) con el sentido de 'mover, menear, agitar'. Por ello, la forma sar-chalabeaos de The Zincali parece una invención de Borrow hecha sobre el modelo del con-mover español, usando la preposición sar 'con' (Quindalé, 1867, s. v. sar) como prefijo. En Dietze no aparece conmovidas ni ninguna forma de conmover, pero sí hallamos en tres ocasiones el verbo chalabear (2012, pp. 173, 174, 177).

\begin{tabular}{|c|c|c|c|c|}
\hline $\begin{array}{l}\text { Embéo (1837: } \\
\text { 150) }\end{array}$ & $\begin{array}{l}\text { The Zincali } \\
\left(1841:{ }^{*} 134\right)\end{array}$ & $\begin{array}{l}\text { Criscote } \\
\text { (1872: 99) }\end{array}$ & $\begin{array}{l}\text { González } \\
\text { Caballero } \\
\text { (1998: 132) }\end{array}$ & $\begin{array}{l}\text { Scío (1926: } \\
119)\end{array}$ \\
\hline $\begin{array}{l}\text { presas as silas } \\
\text { e Tarpe sina- } \\
\text { rán conmo- } \\
\text { vidas }\end{array}$ & $\begin{array}{l}\text { persos los } \\
\text { soláres de los } \\
\text { otarpes que- } \\
\text { san sar-chala- } \\
\text { beaos }\end{array}$ & $\begin{array}{l}\text { presas as silas } \\
\text { e Tarpe sina- } \\
\text { rán chalabea- } \\
\text { das }\end{array}$ & $\begin{array}{l}\text { presas as silas } \\
\text { e tarpe sina- } \\
\text { rán chalabea- } \\
\text { das }\end{array}$ & $\begin{array}{l}\text { porque las } \\
\text { virtudes de } \\
\text { los Cielos } \\
\text { serán conmo- } \\
\text { vidas }\end{array}$ \\
\hline
\end{tabular}

TABLA 15: versículo 26

\section{CONCLUSIONES}

Tras este estudio léxico, destaca, en primer lugar, el hecho de que la fuente de los términos y expresiones españoles que Borrow usa en el fragmento analizado es la edición de Scío, ya que todos ellos son los mismos que usa este autor en su traducción del Evangelio al español (1826, pp. 118-119): demolida en el versículo 6, resistir en el 15, entregados en el 16, aborrecerán en el 17, paciencia en el 19, en medio de en el 21, venganza en el 22, apretura e ira en el 23, filo y bollada en el 24, confusion en el 25 y conmovidas en el $26^{30}$.

\footnotetext{
${ }^{30}$ En cuanto al porcentaje total de palabras españolas que Borrow usa en sus traducciones de San Lucas, el estudio de Dietze, basado, como queda dicho (vid. p. 3, n. 3) en la comparación entre las versiones de Embéo y Criscote de otro fragmento, determina que es del 36,4\% en Embéo y del 31\% en Criscote, así que la diferencia total no es muy llamativa. Sin embargo, hay que tener en cuenta que las categorías que elevan los porcentajes de palabras españolas en Criscote son los nombres propios, las preposiciones, las conjunciones, los pronombres y los determinantes, mientras que las voces españolas con significado pleno presentan un porcentaje claramente inferior: hay un 15,6\% de sustantivos españoles en Embéo y un $4,1 \%$ en Criscote; un $11,5 \%$ de adjetivos en Embéo y un 1,6\% en Criscote; un 10,6\% de
} 
En lo referente a las fuentes de las que pudo tomar Borrow los términos calós para sustituir las voces españolas del Embéo, podemos confirmar, en primer lugar, que resulta complicado rastrearlas. De hecho, hay algunos términos, especialmente los procedentes de The Zincali, que no aparecen en las otras versiones ni en los diccionarios de Pabanó (1915) y Quindalé (1867). Teniendo en cuenta que estos repertorios se basaron en gran medida en el caló del propio Borrow, resulta difícil desenredar la madeja para llegar a saber de dónde provienen los términos desconocidos.

Es evidente que Borrow no pudo usar el diccionario de Quindalé, publicado en 1867, ni para la traducción de Embéo (1837) ni para la de The Zincali (1841). En cuanto a la versión de Criscote (1872), ya hemos visto que Dietze (2012, p. 78) mantiene que sí pudo consultar dicho repertorio español. En este estudio hay datos que refrendan esta teoría, ya que, de las dieciocho voces en español que Borrow cambia en Criscote en el pasaje estudiado, solo tres no aparecen en los diccionarios consultados: detechescada en el versículo 6 (1872, p. 97), miratosas en el 11 (ibid., p. 98) y quichardinipen en el 23 (ibid., p. 99). Las otras expresiones, como queda dicho en el estudio, sí aparecen recogidas en los diccionarios de Quindalé y Pabanó, todas en ambos: diñipenes (versículos 1 y 4, 1872, pp. 146-147), tramisto (versículo 2, ibid., p. 146), presimeláre (versículo 7, ibid., p. 97), Socreterías (versículo 12, ibid., p. 98), chiguatar (versículo 15, ibid., p. 98), binados (versículo 16: ibid., p. 98), orpachirima (versículo 19: ibid., p. 98), curelo pre crejete (versículo 22, ibid., p. 98), tornasibá (versículo 23, ibid., p. 99), mui (24, ibid., p. 99), atelis os pindres (versículo 24: ibid., p. 99), en perplejo (versículo 25, ibid., p. 99), chalabeadas (versículo 26, ibid., p. 99) y presimelaren (versículo 28, ibid., p. 99).

Por otro lado, parece claro que Borrow recurrió a las invenciones de la afición. Si no tomó directamente los términos inventados, bien pudo crearlos

verbos en Embéo y un 4,8\% en Criscote; un 21,4\% de adverbios en Embéo y un 12,3\% en Criscote (Dietze, 2012, pp. 95-96). Esta tendencia a recurrir al español en mayor medida con las palabras funcionales también se refleja de forma notoria en el fragmento aquí estudiado. 
usando sus técnicas. Así lo comprobamos en las siguientes voces, sospechosas cuando menos de haber sido inventadas como calco sobre palabras españolas con las que guardan relación de significado o simplemente un parecido fonético. En efecto, encontramos varias que han sido formadas con el procedimiento de la derivación mediante prefijos o sufijos españoles: el adjetivo chorrorrita 'pobrecita', que hallamos en el versículo 2 de The Zincali (1841, p. *130), presenta el sufijo español de diminutivo ita, al igual que la forma que usa Scío en su texto: «una viuda pobrecita» (1826, p. 80). El mismo sufijo, pero en su forma masculina, aparece también en el versículo 2 en Criscote: nostaritos 'moneditas'. Esta vez Scío traduce "pequeñas monedas" (ibid., p. 80).

El participio demarabeá 'demolida', utilizado en el versículo 6 en The Zincali (1841, p. *130), parece construido sobre el verbo marabear 'moler'.

En el versículo 11 aparece miratosas 'espantosas' en Criscote (1872, p. 97), vocablo que presenta la misma terminación que tiene esa palabra en castellano.

La voz quichartura 'calamidad', que hallamos en el versículo 23 en The Zincali (1841, p. *134), recuerda a apretura, que es la voz que usa Borrow en Embéo (1837, p. 149). No obstante, la raíz quichar-, según atestiguan las voces como quichardila 'mancha' o quichardilar 'manchar', que se recogen en Quindalé (1867, s. v. quichardila, quichardilar) y Pabanó (1915, s. v. quichardila, quichardilar), no parece tener relación clara con el significado 'calamidad' ni guardan semejanza fonética.

Encontramos asimismo voces que son calcos de las palabras españolas con las que comparten significado: en Criscote aparece la expresión querelar jeró 'hacer frente' en el versículo 15 (1872, p. 98). Sustituye al verbo resistir, que es la forma que aparece en Embéo (1837, p. 148) y, curiosamente, en The Zincali como resistír (1841, p. *132). Esta expresión, que consta en Quindalé (1867, s. v. jeró), parece un calco del español hecho sobre la unión de querelar 'hacer' (ibid., s. v. querelar) y jeró 'cabeza, cumbre' (ibid., s. v. jeró). 
En otras ocasiones, los calcos se efectúan sobre parte de la palabra. En unos casos, se pretende traducir una voz española prefijada con una preposición usando el término simple y añadiendo la preposición en caló. Así ocurre en sar-chalabeaos 'conmovidos', que aparece en el versículo 26 en The Zincali (1841, p. *134), palabra que ha sido compuesta sobre el modelo del español, con el participio de chalabear 'mover', según Quindalé (1867, s. $v$. chalabear) y la preposición sar 'con' (ibid., s. v. sar).

El mismo procedimento se detecta en el versículo 26, en el cual encontramos opre abillarán 'sobrevendrán' en Embéo (1837, p. 150), opre-abillarán en Criscote (1872, p. 99) y opreabillarán en González Caballero (1998, p. 132). Estas formas parecen también invenciones hechas sobre el calco del verbo español sobrevenir, con la base del verbo abillar 'venir', según Quindalé (1867, s.v. abillar) más la preposición opré ‘sobre’ (ibid., s. v. opré).

En otros casos, la segmentación sobre la que se opera no es morfológica, sino que se separa arbitrariamente el término español que se quiere traducir para que quede una palabra simple que sí tenga traducción y a la que se le añade el resto de la palabra española. Así ocurre en el versículo 10 de The Zincali, donde aparece la preposición sartra 'contra', que no consta en Quindalé ni en Pabanó. Parece formada a partir de sar 'con' (Quindalé 1867, s. v. sar) más la terminación -tra de la preposición española contra segmentada de forma errónea.

Con el mismo proceder encontramos dos formas del verbo enregar: enregandoós en el versículo 12 de The Zincali, así como enregaos en el versículo 16 (1841, p. *132). Dicho verbo parece una invención hecha sobre el calco del verbo entregar en español, segmentado erróneamente como entre-gar.

Por último, en el versículo 22 consta Abilláza 'venganza' en The Zincali (1841, p. *132). Es posible que Borrow relacionara el término venganza con el verbo venir, por lo que usó el caló abillar 'venir', según Quindalé (1867, s. v. abillar). Asimismo, pudo hacer una falsa segmentación del sufijo español 
-anza interpretando que an formaba parte del verbo (vengan) y dejando solo $z a$, que es lo que añadió finalmente.

Tras analizar estos datos y otros que se desprenden de la lectura de los textos, queda la sensación de que, en realidad, la versión de The Zincali es la más antigua de las tres, a pesar de que, según la fecha de edición de la obra, 1841, sería la segunda. En efecto, llama la atención, en primer lugar, que la mayoría (siete de nueve) de los términos con visos de ser inventados proceden de The Zincali. Esta circunstancia podría explicarse por el hecho de que Borrow no tenía aún suficientes conocimientos o recursos para traducir todas las expresiones necesarias y pudo servirse de estos inventos para completar el trabajo. Asimismo, la versión de 1841 se distingue por ser la que más vacilaciones y errores ortográficos presenta. En efecto, Borrow tomó la decisión de adoptar las grafías del español para consignar el caló, una lengua que no había sido escrita hasta entonces. Dado que su conocimiento del español (o de su ortografía) no debía de ser profundo, cometió una serie de errores, vacilaciones y erratas (a las que habría que sumar las que hubieran podido cometer los cajistas e impresores) cuyo número disminuye en las otras dos versiones.

Esta idea se ve reforzada por el hecho de que el sistema de artículos determinados usado en The Zincali es el más estable y el más parecido al del español, con claro predominio de las formas or, la, los, las y sin contractos, que sí aparecen en las otras versiones. Todo ello podría ser indicio de que, con el tiempo, Borrow fue conociendo otras formas de artículos usados por los gitanos que no eran las españolas y las fue incluyendo en sus obras sin un criterio claro.

Del mismo modo, es evidente que el texto de The Zincali es el que menos se parece a los demás, lo que podría explicarse mejor si lo situamos al inicio de la labor traductora. Quizá fue uno de los primeros textos que compuso, pero, si es así, no está claro por qué no lo recuperó para el Embéo. Si lo revisó para esta versión, publicada en 1837, e introdujo cambios, no se explica por 
qué para la de The Zincali, que data de 1841, no retomó esa versión revisada. Da la impresión de que The Zincali es un batiburrillo ${ }^{31}$ de textos recopilados sin revisión y sin mayor cuidado o hilo argumental.

Parece claro, por tanto, que estos datos confirman la idea de que el caló de Borrow era inestable y fue cambiando a lo largo del tiempo. La existencia de tres versiones tan distintas apunta a que no quedaba contento con ellas y le parecía que debía seguir puliéndolas según iba aprendiendo nuevo vocabulario o nuevas estructuras.

Para concluir estas reflexiones sobre el caló que usa Borrow, podemos decir que dicho autor es, a la vez, la fuente principal para las investigaciones referentes al caló y el origen de varios problemas que se plantean a la hora de estudiar esa lengua. Esto es así porque no contamos con ningún otro documento del calado de los textos de Borrow, ya sean las traducciones del Evangelio o los poemas, las coplas y el listado de términos recogidos en The Zincali. Es evidente que conservó un corpus lingüístico que se habría perdido de no haber sido por su interés en el tema. En efecto, el estado del caló en el siglo XIX era desesperado y actualmente es una lengua muerta. Podemos decir con Clavería (1951, pp. 10-11) que tanto los textos como las apreciaciones de Borrow siguen siendo básicos para cualquier estudio del caló.

\section{BIBLIOGRAFÍA}

\section{Obras originales de George Borrow}

Borrow, G. (1837). Embéo e Majaró Lucas, brotoboro randado andré la chipé griega, acana chivado andré o Romanó, o chipé es Zincales de Sesé. El Evangelio según S. Lucas, traducido al Romani, ó dialecto de los Gitanos de España. Madrid: Imprenta de don Andrés Borrego.

Borrow, G. (1841). The Zincali; or, An account of the Gypsies of Spain with original collection of their songs and poetry, and a copious dictionary of their language, by George Borrow, late agent of the British and Foreign Bible Society. In two volumes. London: John Murray.

${ }^{31}$ Un gazpacho, como dice Knapp (1899, I, p. 350). 
Borrow, G. (1872). Criscote e Majaró Lucas, chibado andré o Romano, ó chipé es Zincales de Sesé. El Evangelio según S. Lucas, traducido al Romaní, ó dialecto de los Gitanos de España. Lundra: Clowes and Soke.

Borrow, G. (1901³ [1851]). Lavengro. The Scholar, the Gypsy, The Priest. London: Methuen \& Co.

\section{Estudios y otras obras citadas}

Adiego, I. (2004). Del romaní comú als calós ibèrics, en Llengua ELiteratura, 15, pp. 211-236.

Adiego, I. (2005). The first Caló dictionary ever published in Spain (Trujillo 1844): An analysis of its sources, en Romani Studies, 2005, 15, 2, pp.125-143.

Adiego, I. (2008). When George Borrow met Spanish Romani, en George Borrow Bulletin, 36, pp. 15-28.

Adiego, I. y Martín, A. (2006). George Borrow, Luis de Usoz y sus respectivos vocabularios gitanos, en Revista de Filología Española, 86, 1, pp. 7-30.

Bullen, G. (1857). Catalogue of the Library of the British and Foreign Bible Society. London: Reed and Pardon, Paternoster Row.

Buzek, I. (2008): "Anotaciones del proyecto Tesoro léxico del caló", en D. Azorín Fernández (ed.): El diccionario como puente entre las lenguas y culturas del mundo. Actas del II Congreso Internacional de Lexicografía Hispánica, Alicante, Fundación Biblioteca Virtual Miguel de Cervantes, pp. 500-505.

Buzek, I. (2010). La imagen del gitano en la lexicografía española. Brno: Masarykova Univerzita.

Buzek, I. (2011). Historia crítica de la lexicografía gitano-española. Brno: Masarykova Univerzita.

Buzek, I. y Krinková, Z. (2020). El caló español a comienzos del siglo XXI: el estado de la cuestión, en Études Romanes de Brno, 41, pp. 159-177.

Clavería, C. (1951). Estudios sobre los gitanismos del español. Madrid: CSIC.

Dietze, M. (2012). Die Lukasevangelien auf Caló: Die Ursachen ibrer Sprachinterferenz und der Anteil des Spanischen [Tesis doctoral], TU Dresden, Fakultät für Sprach-, Literaturund Kulturwissenschaften, Institut für Romanistik [https://n9.cl/7o36w, publicada en 2017 por la editorial AV Akadamikervelag].

González Caballero, A. (1998). El evangelio de San Lucas en caló, edición bilingüe caló-castellano. Córdoba: El Almendro.

Hancock, I. (1997). George Borrow's Romani, en Y. Matras, P. Bakker y K. Hristo (Eds.), The typology and dialectology of Romani, Amsterdam: John Benjamins, pp. 199-214.

Jenkins, H. (1912). The Life of George Borrow. Compiled from unpublished oficial documents, his works, correspondence, etc. London: John Murray. 
Jiménez González, N. (2009). ¿El romanó, el caló, el romanó-kaló o el gitañol? Cincuenta y tres notas sociolingüísticas en torno a los gitanos españoles, en Anales de Historia Contemporánea, 25, pp. 149-161.

Knapp, W. (1899). Life, Writings an Correspondence of George Borrow (1803-1881). London: John Murray.

Krinková, Z. (2015). From Iberian Romani to Iberian Para-Romani Varietes. Praga: Karolinum Press.

Matras, Y. (2002). Romani. A Linguistic Introduction. Cambridge: Cambridge University Press.

Pabanó, F. (1915). Historia y costumbres de los gitanos. Colección de cuentos viejos y nuevos, dichos y timos graciosos, maldiciones y refranes netamente gitanos. Diccionario español-gitano-germanesco. Dialecto de los gitanos. Barcelona: Montaner y Simón.

Quindalé, F. (1867). El gitanismo. Historia, costumbres y dialecto de los gitanos. Con un epítome de gramática gitana, primer estudio filológico publicado hasta el día, y un diccionario caló-castellano, que contiene, además de los significados, muchas frases ilustrativas de la acepción propia de las palabras dudosas. Valencia: Librería París-Valencia.

Scío, F. (1826² [1790]). El Nuevo Testamento, traducido al espanol de la Vulgata Latina, por el Rmo. P. Phelipe Scio de S. Miguel, de las Escuelas Pías, Obispo Electo de Segovia. Londres: T. C. Hansard, Pater-Noster-Row.

Shorter, C. (1913). George Borrow and his Circle. Wherein May Be Found Many Hitherto Unpublished Letters of Borrow and His Friends. Boston/New York: Houghton Mifflin Company.

Thomas, E. (1912). George Borrow. The man and his books. London: Chapman \& Hall Ltd. 